\title{
Revista \\ Triângulo \\ FORMAÇÃO, SABERES E PRÁTICAS DOCENTES NA ESCOLA INCLUSIVA EM CONSTRUÇÃO
}

\author{
EDUCATION, KNOWLEDGE AND PRACTICE IN INCLUSIVE SCHOOL TEACHERS \\ IN CONSTRUCTION
}

\author{
Maria Inês de Almeida Pelegrine ${ }^{1}$ e Carla Helena Fernandes ${ }^{2}$
}

\begin{abstract}
RESUMO
O estudo objetivou investigar ações docentes nos anos iniciais do Ensino Fundamental na inclusão de alunos público-alvo da Educação Especial na classe comum. A inclusão escolar, um grande projeto internacional e nacional ainda em construção, tem solicitado a organização de ambientes educacionais adequados à aprendizagem escolar, no ensino regular, de todos os alunos, inclusive aqueles com necessidades educacionais especiais. Na pesquisa, de abordagem qualitativa, realizou-se entrevista semiestruturada com catorze professores de três escolas públicas estaduais, localizadas em Pouso Alegre- MG. Os resultados indicaram, por um lado, que algumas ações docentes ainda refletem o processo de exclusão historicamente construído; por outro, evidenciaram práticas em reconstrução que têm em perspectiva os alunos, como sujeitos deste processo, em suas características e potencialidades. As mudanças necessárias têm em vista atender a atual solicitação feita à escola como partícipe da construção de uma sociedade e educação com mais equidade. Neste processo, a formação profissional continuada é indicada como ferramenta fundamental.
\end{abstract}

PALAVRAS-CHAVE: Formação. Saberes docentes. Prática pedagógica. Educação inclusiva.

\begin{abstract}
The study aimed to investigate teachers' actions in the inclusion of students who belong to the Special Education in the common class during the early years of elementary school. School inclusion, a large international and national project still under construction. It has needed organization of educational environments appropriate for school learning in regular education of all students, including those with special educational needs. In the survey, a qualitative approach was carried out semi-structured interviews with fourteen teachers from three public schools located in Pouso Alegre-MG. Some results indicate, that some teachers' actions also reflect the deletion process historically constructed; some others results showed practices in reconstruction that have prospective students as subjects of this process in its features and capabilities. The necessary changes are intended to meet the current request made to the school as a participant of building a society and education with more equity. In this process, continuing vocational training is indicated as a fundamental tool.
\end{abstract}

KEYWORDS: Training. Knowledge teachers. Teaching practice. Inclusive education.

\section{INTRODUÇÃO}

A diversidade humana e os grupos de escolares têm sido a motivação para muitos estudos na atualidade, impulsionando a formação dos professores na perspectiva de uma

$1 \quad$ Universidade do Vale do Sapucaí - UNIVÁS. E-mail: ines.pelegrini@ifsuldeminas.edu.br

2 Universidade do Vale do Sapucaí - UNIVÁS. E-mail: carlahelenafernandes@yahoo.com.br 
prática educativa que auxilie na ressignificação dos saberes docentes e que direcione o ser/fazer do professor no sentido do respeito às diferenças individuais. Evidencia-se que essa diversidade que adentra os muros da escola tem promovido o repensar dos seus espaços e tempos, evidenciando a necessidade de se buscar condições favoráveis à construção de uma educação efetivamente inclusiva. Essa construção, a partir dos anos 1990, tem sido reconhecido como uma política educacional prioritária, nacional e internacionalmente, tendo como princípio básico o acesso de todos alunos à escola regular, independente de qualquer condição que tenham, devendo a escola se adequar para atender suas necessidades educacionais. (GLAT; PLETSCH; FONTES, 2007).

A pesquisa foi desenvolvida junto a professores dos anos iniciais do ensino fundamental que atuam em escolas públicas estaduais de Pouso Alegre - MG e objetivou investigar os saberes desses professores sobre o ensino para alunos público-alvo da Educação Especial. ${ }^{\mathrm{i}}$.Nesta perspectiva, a investigação partiu das seguintes questões: que saberes têm os professores de classes comuns sobre o ensino para alunos com necessidades educacionais especiais? Que práticas pedagógicas desenvolvem em sala de aula especificamente? $\mathrm{Na}$ percepção dos professores, em que medida a sala de aula e a prática pedagógica desenvolvida mobilizam a reconstrução de seus saberes?

A ação pedagógica se caracteriza como espaço-tempo da construção/reconstrução dos saberes docentes. Na perspectiva de um continuado processo de ensinar e aprender, pautado em diferentes saberes, os professores reconstroem concepções e práticas. Resulta desta pesquisa a ideia de que os saberes e o fazer docentes são fundamentais na construção da inclusão educacional, preconizada pela legislação em seu movimento universal, a educação para todos.

\section{Saberes e formação docente}

Os saberes docentes são múltiplos e podem ser definidos "como plural formado pelo amálgama, mais ou menos coerente, de saberes oriundos da formação profissional, dos saberes das disciplinas, dos currículos e da experiência" (TARDIF, 2012, p. 36), que são confrontados e mobilizados pelos professores de acordo com a realidade de sua prática profissional. Desta forma, pode-se entender que a ação pedagógica envolve os diferentes saberes inerentes à ação docente, a saber: os saberes da formação profissional, constituídos pelas ciências da educação e que compreendem a formação inicial e continuada e os saberes 
construídos ao longo da carreira; os saberes disciplinares, identificados nos diferentes campos do conhecimento produzidos pela humanidade e disponibilizados pelas instituições de ensino; os saberes curriculares, que são geridos pelas instituições educacionais e repassados aos alunos através de programas com objetivos, conteúdos e métodos aplicados pelos professores e, finalmente, os saberes experienciais, resultantes do exercício da profissão docente no âmbito escolar que, "incorporam-se à experiência individual e coletiva sob a forma de habitus e de habilidades, de saber-fazer e de saber o ser" (TARDIF, 2012, p. 38).

Esta ideia da pluralidade dos saberes é reafirmada por Gauthier (2013, p. 20) que afirma que "uma das condições essenciais a toda profissão é a formalização dos saberes necessários à execução das tarefas que lhe são próprias", o que dá forma a um reservatório que poderá sustentar e trazer respostas ao trabalho cotidiano dos professores. É importante que se reflita na perspectiva de que esse abastecimento não comporta apenas uma reserva, mas uma reelaboração contínua pelos professores, numa perspectiva formativa e em contínua interação com os demais professores e com o contexto escolar.

Os saberes docentes, contextualizados e fundamentados no próprio processo formativo, indicam a necessidade do aprofundamento teórico, bem como dialógico reflexivo na e sobre a prática, em processo de contínua reconstrução. Para Pimenta (2005, p. 8), mobilizados pelo exercício docente os professores podem desenvolver "a capacidade de investigar a própria atividade e, a partir dela, constituírem e transformarem seus saberes/fazeres docentes"

A ressignificação do saber/fazer docente é importante no desenvolvimento profissional docente e a escola pode ser considerada como um espaço social privilegiado onde são produzidos, divulgados e partilhados os saberes dos professores. A dialética teoria/prática se evidencia nesse contexto e, como afirma Mota (2005, p.78), “não podemos descartar os conhecimentos teóricos, científicos e acadêmicos, nem por outro lado, considerar os saberes da prática como autossuficientes para a formação dos professores”. Implica, portanto, em uma relação contínua de formação em que a teoria e prática se complementam de forma dialética.

Para ressignificar saberes, é preciso abertura para o novo, libertar-se de preconceitos e disponibilidade em ampliar e desenvolver novas habilidades que atendam às exigências de um ser/saber/fazer didático diverso e inclusivo. A ação docente é diversa e "o problema principal do trabalho docente consiste em interagir com alunos que são tão diferentes uns dos outros, mas estão juntos, reunidos por uma educação escolar que os congrega em turmas, 
níveis de ensino e disciplinas, cumprindo um currículo comum. É neste contexto que trabalham os professores na escola.

Neste aprimoramento em busca de (re)construção de saberes que respondam às necessidades da escolarização atual dos alunos, a formação continuada deve ter destaque voltado para a prática e a ação reflexiva na docência. A formação, portanto, deve “[...] estimular uma perspectiva crítico reflexiva que forneça, aos professores, os meios de um pensamento autônomo e que facilite as dinâmicas da autoformação participada" (NÓVOA, 1995, p. 25). Neste contexto de formação coletiva, há que se considerar a reflexão na/sobre a prática como uma fonte de conhecimentos e alicerce para a construção de novos saberes como fundamentação de respostas à complexidade da ação educativa.

$\mathrm{Na}$ perspectiva da formação, o reconhecimento do saber da experiência, "conduz a valorizar, também, a heterogeneidade dos processos formativos. É a reflexão, conduzida de modo sistemático e finalizada que permite transformar a experiência num saber utilizável", (CANÁRIO, 1994, p.16). Contudo, reconhecendo o contexto singular das escolas, com suas possibilidades e limites, podemos afirmar que a formação, os saberes produzidos e ressignificados pelos professores são necessários no atendimento às diferentes necessidades educacionais dos alunos, princípio afirmado pela Declaração de Salamanca (UNESCO, 1994), como indicativo de identidade profissional docente na perspectiva histórico-social que se recontextualiza no âmbito educacional contemporâneo.

\section{Metodologia}

O presente estudo contextualiza-se no âmbito da pesquisa qualitativa que se caracteriza pelo estabelecimento de relações entre a situação investigada, o contexto e sujeitos participantes, visando investigar essas relações em ambiente natural como a principal fonte de dados (BOGDAN; BIKLEN, 1994). Nesta forma de investigação, é relevante o significado que as pessoas envolvidas atribuem ao objeto investigado e se deve retratar efetivamente a perspectiva dos participantes (LÜDKE; ANDRÉ, 1986)

O encaminhamento metodológico da pesquisa desenvolvida teve como suporte uma pesquisa documental possibilitando uma relação transversal entre as ações do professor, a escola e a rede estadual de ensino na busca na compreensão dos saberes docentes na inclusão escolar de alunos público-alvo da Educação Especial. Para tal, foi utilizado como procedimento de investigação a entrevista semiestruturada realizada com catorze professores 
que, em 2013 e 2014, atuavam nos anos iniciais do Ensino Fundamental ( $1^{\circ}$ ao $5^{\circ}$ ano) e que ensinavam para alunos com deficiência.

Todos os sujeitos da pesquisa são do sexo feminino ${ }^{\text {ii }}$ e é uma população relativamente jovem, se considerar que apenas três dos catorze professores têm mais de 50 anos de idade.

Os dados levantados nas entrevistas foram analisados buscando-se pela emergência de temas e subtemas, tendo-se como referência o referencial teórico da pesquisa.

\section{Formação e saberes docentes na perspectiva inclusiva: resultados e discussões}

Explicitar o posicionamento, as dúvidas e reflexões sobre a ação docente, a partir dos próprios professores é fundamental para traçar considerações acerca da sua formação na perspectiva da inclusão escolar. Como se sabe, e essa pesquisa reafirma, a inclusão escolar não tem acontecido sem resistências, porém também indica a busca pela construção de adequado atendimento pedagógico para os alunos público alvo da educação especial, o que a pesquisa realizada também evidenciou.

$\mathrm{Na}$ sequência, apresentamos e discutimos com apoio no referencial teórico, as falas das professoras participantes da pesquisa sobre seu processo de formação em vista a uma escola e prática pedagógica inclusiva. A discussão será organizada em dois subtemas, a saber: 1. a formação continuada mobilizada pelo trabalho com alunos público-alvo da educação especial, em que se apresentam as falas das professoras acerca da construção da prática pedagógica inclusiva, afirmando que aos conhecimentos adquiridos na formação acadêmica foi agregada a experiência cotidiana, e 2. a formação promovida pela rede de ensino, que discute acerca da prática pedagógica dos docentes.

\section{A formação continuada mobilizada pelo trabalho com alunos público-alvo da educação especial}

$\mathrm{Na}$ busca pela construção da prática pedagógica que efetivamente atenda às necessidades de seus alunos, as professoras ${ }^{\mathrm{iii}}$ afirmaram que, além dos conhecimentos adquiridos na formação acadêmica, a experiência cotidiana, os saberes (re)construídos na prática, no exercício da profissão são também na construção de suas ações, evidenciando a própria participação dos alunos nesse processo. O saber/fazer docente tem seu lócus de 
construção no âmbito escolar, portanto, "os saberes profissionais são personalizados e situados" (TARDIF, 2012, p. 264) porque são incorporados e subjetivados pelo professor e constituídos no contexto particular onde têm sua significação. As professoras, nos excertos apresentados na sequência, dizem sobre a formação na/da interação com os alunos e na experiência que adquirem ao enfrentar os desafios pedagógicos..

Quando recebemos essas crianças, vamos adquirindo novas experiências. Ao trabalhar com esses alunos descobrimos uma nova, nova metodologia para trabalhar com eles. (Klein)

No começo eu achei que não ia dar conta, que ia ser muito difícil, mas ai, depois, com o dia a dia, a gente aprende muito com eles. (Nany)

Do jeito que for você só vai aprender com a criança. O que você vai dizer agora? O que eu vou fazer, mas você aprende junto com a criança a como lidar com ela. (Matildes)

Dos relatos das professoras depreende-se a disposição para a formação no trabalho, considerando a prática cotidiana, admitindo que, na interação com os alunos, de onde emergem novas/outras questões sobre o fazer pedagógico, ressignificam sua prática. $\mathrm{O}$ professor está continuamente se formando e (re)construindo saberes quando abre espaço no seu trabalho para situações de ensino que lhe permitam melhor conhecer o aluno, situações que propiciarão aprender com ele em função de um melhor desenvolvimento e aprendizagem do mesmo.

Esta prática reflexiva se constrói à favor da ação pedagógica que, de forma cíclica, realiza o confronto da prática com referenciais teóricas que proporcionam a revisão do saber/fazer, favorecendo a realização de estratégias interventivas, capazes de mobilizar os conhecimentos do educador a partir da reflexão.

No dinamismo que se apresenta à ação educativa a professora afirma sobre avanços, mas também sobre as dificuldades que a impulsionam a novas buscas.

Falta preparo do professor para determinada situação. Um ano você está acostumado a atender um aluno com uma necessidade e no outro você tem outro com outra necessidade. Então você tem que estar sempre se informando, estudando para ver qual melhor recurso, o que você pode fazer para ajudar e tem professor que não está preparado. (Kelly)

A professora Kelly apresenta o sentimento do despreparo para trabalhar com os alunos com diferentes necessidades educacionais mas, predisposta a ressignificar saberes, demonstra abertura para atuar "sempre se informando, estudando para ver qual o melhor 
recurso" a ser utilizado na prática e buscando formação continuada. Os professores ressignificam diariamente sua ação, "adquirem essa consciência à medida que refletem sobre e a partir de sua prática, condição para construírem novos saberes e para modificarem suas práticas. Ou seja, para teorizarem" (PIMENTA, 1996, p. 62). O saber/fazer do professor tomado pela rotina da sala de aula se torna automatizado e a transformação de suas práticas e a construção de novos saberes acontecem por meio da reflexão na e sobre sua ação docente.

A formação continuada é imprescindível no contexto educacional, como bem pontua a professora no excerto apresentado na sequência.

É mais questão de formação, tanto é que eu estou buscando a formação, porque o que a gente vê na Faculdade não é o suficiente. De certa forma, a educação inclusiva não é nova, mas agora que veio para a escola pública, a gente tem que buscar formação, porque não saímos formadas. Mesmo que você aprenda na prática, você precisa da teoria, você precisa da formação, do conhecimento, dessa partilha e dessa mediação. (Cátia)

Nesta perspectiva, "é preciso investir positivamente os saberes de que o professor é portador, trabalhando-os de um ponto de vista teórico e conceptual” (NÓVOA, 1992, p. 27), resgatando saberes evidenciados na prática docente construídos na experiência; na interação com seus pares e alunos em condições concretas de ensino-aprendizagem, numa perspectiva pedagógica que se pretende, dialógica e inclusiva.

É no exercício da profissão docente que a autoria desse profissional é construída, pois "o professor, conhecido e reconhecido como autor, no exercício da docência, observa, sistematiza e reflete sobre seu fazer e saberes em interlocução com outros sujeitos, alunos e demais professores”. (FERNANDES, 2014, p.19). Contexto que contribui para seu exercício neste movimento de contínuas transformações sociais e políticas, que alavancam também mudanças educacionais, trazendo consigo novas demandas educacionais e de aprendizagem.

\section{A formação promovida pela rede de ensino}

A formação docente no atual contexto educacional implica que a experiência e as novas solicitações pedagógicas na realidade escolar sejam contempladas passando pelo âmbito da investigação científica articulada com as práticas. Os professores são atores fundamentais na reforma educacional e construção de processos educacionais mais inclusivos na escola regular. A formação docente solicita uma ação constantemente planejada em função 
das necessidades cotidianas do contexto escolar, o que também é decorrente das políticas educacionais.

Neste contexto, é necessário que as instituições possibilitem espaços de formação docente levando em consideração que "pensar e organizar os processos de trabalho faz apelo a novos tipos de saberes, nomeadamente: trabalhar em equipe, pensar à escala da organização no seu todo, agir estrategicamente a partir de raciocínios de antecipação" (CANÁRIO, 1994, p. 4). Através do trabalho coletivo e compartilhado pela equipe da escola, as ações educativas tendem a ser mais pontuais e assertivas.

A formação dos professores é um espaço/tempo de reflexões sobre o ensino pautado pela diversidade visando que seja acessível a todos os alunos. Nesse contexto as professoras resgataram suas experiências, sobre o que se expressaram:

As orientações que nós recebemos são passadas nos Módulos ${ }^{i v}$ dos quais participamos e no atendimento individual com a supervisora para tratar especificamente da dificuldade daquele aluno que nós recebemos naquele ano. (Fátima)

A rede trabalha mais com o professor da sala de recurso ${ }^{v}$. Não estamos assim preparados, faltam muitos cursos direcionados para os vários tipos de deficiência. Então tem criança que vem e a escola não oferece totalmente os meios para você. É você é que deve ir buscando. ((Klein)

Nesta perspectiva é preciso que a formação, de fato, seja continuada para que o contexto das práticas seja transformado e ressignificado por novos saberes. As professoras afirmaram no contexto da rede em que atuam as limitações e as necessidades prementes para sua atuação. A professora Fátima expressou sobre o Módulo de Estudo e delimitou sua ação de forma pontual. A professora Celeste, falou sobre a necessidade de conhecimentos teóricos através de cursos, por meio da aquisição de um novo quadro de referenciais que as ajudem a reconhecer as necessidades educacionais de seus alunos. Nesta perspectiva, a rede também precisa atender, além dos professores especializados das salas de recurso (professores do AEE - Atendimento educacional Especializado), ao processo de formação dos professores da classe regular.

Ainda em relação aos Módulos de Estudo, as professoras afirmaram:

Através dos módulos que são feitos na escola são repassados para gente, [orientações] e aí a gente é informada sobre o que está acontecendo, como deve agir e a gente tenta trabalhar. (Luciana) 
Eu queria ser mais orientada, ter alguém que viesse nos Módulos dar mais orientação, como trabalhar; a gente sabe mais ou menos, procura ler um pouquinho na internet, correr atrás também do saber como trabalhar, se não, chegamos à sala e ficamos desmotivadas sem conseguir. (Celeste)

As falas das professoras evidenciaram que esses momentos, embora sejam compreendidos como de formação continuada - como explicita a professora: "a gente é informado sobre o que está acontecendo, como deve agir e a gente tenta trabalhar" (Luciana)- também indicam a necessidade de que sejam utilizados voltados especificamente ao atendimento das necessidades (in) formativas dos professores - "ter alguém que viesse nos Módulos dar mais orientação, como trabalhar; a gente sabe mais ou menos" (Celeste).

A formação do professor se torna uma tarefa complexa conjugando o desenvolvimento profissional e o amadurecimento do professor articulando a dimensão da individualidade e da diversidade dos alunos que compõem o grupo aula. A ação docente, "não muda por decreto ou por norma. Ela muda quando o sujeito percebe a necessidade de mudar e percebe também que possui condições favoráveis para tal” (FRANCO, 2013, p. 10). Portanto, o processo educativo para além de orientações, (in) formações e cursos deve constituir-se em um processo conjugado de ações internas do professor e do contexto educacional viabilizado pela rede.

O processo de formação continuada contribui para a ressignificação de saberes docentes voltados para práticas pedagógicas mais inclusivas, para além das prescrições e determinações, lembrando que os processos inclusivos sugerem atos coletivos, bem como abertura para novas concepções desvelando sentimentos e desconstruindo preconceitos.

\section{CONCLUSÃO}

Entre os muitos aspectos envolvidos na construção de educação e escolas inclusivas, a formação docente emerge como um tema central. É preciso que os professores revejam conceitos adquiridos na formação inicial. Essa ressignificação não se dá a priori, mas no exercício docente, no cotidiano das salas de aula (TARDIF, 2012; GAUTHIER, 2013), no encontro com os alunos, entre os quais, aqueles que solicitam da escola e dos profissionais um atendimento específico às suas necessidades.

$\mathrm{Na}$ pesquisa desenvolvida, a formação também emergiu da fala das professoras afirmando não se sentirem preparadas para trabalhar com a inclusão escolar. Compreendemos que este discurso do despreparo deve ser considerado no contexto da sua produção e 
compreendido como sentidos que emergem da realidade histórico-social, educacional e política construída/desconstruída individual e coletivamente. As professoras falaram sobre a formação pela experiência, valorizando os saberes constituídos ao longo da carreira, mas também indicaram a necessidade de cursos e de outras formas de formação continuada, mas que essas tenham como foco a realidade posta às professoras.

$\mathrm{Na}$ construção de educação inclusiva, a reflexão favorece a ressignificação dos saberes transformando práticas homogeneizadoras em educação que contemple as diferenças, o que está em construção. Neste processo esforços coletivos se fazem necessários: das instituições, sistemas, escolas e profissionais.

Conforme Decreto n $7.611 / 2011$ “considera-se público-alvo da educação especial as pessoas com deficiência, com transtornos globais do desenvolvimento e com altas habilidades ou superdotação". (BRASIL, 2011)

ii Em função deste dado, a partir deste trecho serão referenciados como professora/s.

iii Os excertos das entrevistas foram identificados com nomes fictícios que deram voz às professoras.

iv Os chamados Módulos de Estudo, se constituem de encontros semanais de estudo coletivos, entre a supervisora pedagógica da escola e os professores. Momentos de formação continuada, em que as professoras recebem e trocam informações e experiências, podem de fato constituir-se em momentos singulares de convivência e reflexão coletiva.

v A sala de recursos multifuncionais é o espaço do AEE _ Atendimento Educacional especializado, realizado no contraturno. Conforme Decreto $n^{0}$ 7.611/2011 estes serviços são "denominados atendimento educacional especializado, compreendido como o conjunto de atividades, recursos de acessibilidade e pedagógicos organizados institucional e continuamente" (BRASIL, 2011).

\section{REFERÊNCIAS}

BOGDAN, R.; BIKLEN, S. Investigação qualitativa em Educação. Porto: Porto Editora, 1994.

BRASIL. Presidência da República. Casa Civil. Subchefia para Assuntos Jurídicos. Decreto presidencial $n^{0} 7.611$ de 17 de novembro de 2011. Brasília, 2011. Dispõe sobre a educação especial, o atendimento educacional especializado e dá outras providências. Disponível em: $<\mathrm{http}$ ://www.planalto.gov.br/ccivil 03/Ato2011.../2011/Decreto/D7611.htm>. Acesso: 9 set. 2015 .

CANÁRIO, R. Gestão da escola: Como elaborar o plano de formação? Lisboa: Instituto de Inovação Educacional, 1994. 
FERNANDES, C. H. Pesquisa e formação profissional continuada: (em) caminhos da educação inclusiva. Educação: Teoria e Prática, Rio Claro. v. 24, n.46, p. 04-22, maio/ago. 2014.

FRANCO, M. A.S. Didática: uma esperança para as dificuldades pedagógicas do ensino superior? In: $36^{\mathrm{a}}$ REUNIÃO NACIONAL DA ANPEd - 29 de setembro a 02 de outubro de 2013, Goiânia-GO. Disponível em: $<$ http://36reuniao.anped.org.br/ pdfs trabalhos aprovados/gt04_trabalhos_pdfs/gt04_2699_texto.pdf.>. Acesso em: 09 set. 2015.

GAUTHIER, C. et al. Por uma teoria da pedagogia: pesquisas contemporâneas sobre o saber docente. 3. ed. Ijuí: Ed.Unijuí, 2013.

GLAT, R.; PLESCH, M. D.; FONTES, R. S. Educação inclusiva \& educação especial: propostas que se complementam no contexto da escola aberta à diversidade. Educação, Santa Maria (RS), v. 32, n. 2, p. 343-356, 2007.

LÜDKE, M.; ANDRÉ, M. E. D. A. Pesquisa em educação: abordagens qualitativas. São Paulo: EPU, 1986.

MOTA, E. A. D. Saberes e conhecimentos docentes: experiências da formação e experiências da profissão. Dissertação (Mestrado em Educação) - UNICAMP, Campinas, 2005.

NÓVOA, A. Os professores e sua formação. Lisboa: Nova Enciclopédia, 1992.

O passado e o presente dos professores. In. Nóvoa, A. (org.) Profissão Professor. Porto: Porto Editora, 1995. p.13-34.

PIMENTA, S. G. (Org.) Didática e formação de professores: percursos e perspectivas no Brasil e em Portugal. São Paulo: Cortez, 1996. 255p.

Formação de Professores: identidade e saberes da docência. In: . (Org.) Saberes pedagógicos e atividade docente. São Paulo: Cortez, 2005.

TARDIF, M. Saberes docentes e formação profissional. 14. ed. Petrópolis: Vozes, 2012.

UNESCO. Declaração de Salamanca e Enquadramento da Ação na Área das Necessidades Especiais. In: Conferência Mundial sobre Educação para as Necessidades Especiais: Acesso e Qualidade, Salamanca. Disponível em: $<\mathrm{http}$ ://www.portal.mec.gov.br/seesp/arquivos/pdf/ salamanca.pdf>. Acesso: 9 set. 2015.

RECEBIDO EM: 10/03/2016

APROVADO PARA PUBLICAÇÃO EM: 29/11/2016 